\title{
Posture restrictions do not interfere in the results of canalith repositioning maneuver
}

\section{Lucinda Simoceli ${ }^{1}$, Roseli Saraiva Moreira Bitta ${ }^{2}$, Mário Edvin Greters ${ }^{1}$}

Key words: benign paroxysmal positional vertigo, Epley maneuver, dizziness.

\section{Summary}

B

enign Paroxysmal Positional Vertigo (BPPV) is a frequent cause of dizziness and despite of the excellent results with its treatment, there is some controversy about management. Aim: To assess the efficacy of Epley Maneuver with and without post-maneuver restrictions. Study Design: Prospective randomized. Material and Method: Fifty patients presenting BPPV of the posterior semicircular canal, treated with Epley Maneuver and divided into two groups: study group - 23 patients - with post-maneuver restrictions, and control group - 27 patients - without post-maneuver restrictions. Results: No significant difference was found between the studied and the control group. Conclusion: Post-maneuver restrictions do not influence the efficacy of Epley Maneuver for BPPV management.

${ }^{1}$ Collaborating Physician, Sector of O toneurology, HCFMUSP

${ }^{2}$ Assistant Physician, Sector of O toneurology, HCFMUSP.

Discipline of O torhinolaryngology, Hospital das Clínicas da FMUSP.

Address correspondence to: Lucinda Simoceli / Depto de ORL do HCFMUSP - R. Dr. Enéas de Carvalho Aguiar, $2556^{\circ}$ andar sala $602105403-000$ Sao Paulo, SP Brazil. - E-mail: Isimoceli@ig.com.br

Article submited on August 10, 2004. Article accepted on November 10, 2004. 


\section{INTRODUCTION}

Benign Paroxysmal Positional Vertigo (BPPV) is defined as a vestibular syndrome of peripheral origin characterized by short and intensive episodes of vertigo, associated with predominantly horizontal-rotation nystagmus, triggered by quick change of head position ${ }^{1}$. In addition to the characteristics described, symptomatology of BPPV may include imbalance, sensation of light head and nausea. Crises are normally triggered by sudden changes in head position, getting up from bed or rotating around the body. The incidence varies in epidemiological studies from 11 to 64 per 100,00/year ${ }^{2,3}$.

BPPV is one of the most common diseases of the inner ear, reported in the literature as being responsible for approximately $17 \%$ of the clinical diagnoses of dizziness ${ }^{4,5}$. It may be found in all age ranges, but it increases with aging ${ }^{6}$ and in idiopathic cases, its peak of incidence is within 50 and 70 years ${ }^{1}$, despite the fact that it is part of the differential diagnosis of vertigo in children ${ }^{7}$. In a recent cross section study conducted by the Division of O toneurology, HCFMUSP, diagnosis of BPPV amounted to $15 \%$ of the etiologies of dizziness in the population older than 65 years 8 .

In 50 to $70 \%$ of the cases, BPPV is idiopathic or primary 5 , and the second most common cause is head trauma that corresponds to 7 to $17 \%$ of cases ${ }^{4,6}$. Vestibular neuronitis is associated with approximately $15 \%$ of the cases ${ }^{6}$ and Ménière's disease is present between $0.5 \%$ and $31 \%$ of BPPV 9,10 . Authors such as Gross ${ }^{11}$, conversely, observed that approximately $5.5 \%$ of the patients with Ménière's disease presented typical BPPV of posterior semicircular canal and these cases were of difficult clinical control of positional symptomatology. Ishiyama ${ }^{12}$ and Lempert ${ }^{13}$ have recently described the association between migraine and cause of BPPV in $5 \%$ of the cases, as observed in most of the children in the study by Uneri'. BPPV may be associated with inner ear surgeries in $1 \%$ of the cases, and the highest risk for its development is detected in stapes surgeries (stapedectomy and stapedotomy) ${ }^{14,15}$.

The clinical pathology substrate corresponding to BPPV was proposed by Schuknecht ${ }^{16}$ in 1962, which described the presence of crystals coming from utriculus macula, which are released and then adhere to the top of posterior semicircular canal (cupololithiasis). Some years later, Hall et al. ${ }^{17}$ proposed the canalith therapy, which comprises the increase of endolymph density caused by the presence of free suspension particles. BPPV may be originated from any semicircular canal, but the posterior canal is the most frequently affected in the majority of cases. The natural clinical course of BPPV is self-limited and takes from weeks to months, and it normally does not respond to antivertigo drugs ${ }^{18-20}$. Advocated treatments are various: maneuvers of canalith repositioning Epley maneuver is the most common one ${ }^{21}$, liberatory maneuvers, Semont ${ }^{22}$ maneuver, vestibular habituation training
23-25, and surgical treatments such as singular neurectomy or occlusion of posterior semicircular canal that are reserved to cases non-responsive to clinical treatment ${ }^{26,27}$.

In its first description of the maneuver of the posterior semicircular canal reposition, Epley ${ }^{21}$ recommended the use of bone vibration, care with posture restriction and head movement after treatment. These guidelines intended to prevent the return of the repositioned particles to the released semicircular canals. Among them, there are recommendations to sleep sitting up or with head inclination of $45^{\circ}$ (reclined armchair or the use of 2 pillows) for 48 hours after the maneuver. Some studies ${ }^{5,28}$ recommend elevated lying down position after the maneuver for 7 days, period in which the patient should avoid sudden movements and those that trigger dizziness, not to sleep over the affected ear, and not to look up or down ${ }^{29}$. Some authors suggest that patients should wear a neck collar to prevent head movements $24,30,31$.

Clinical experience suggested that regardless of the repositioning maneuver or the chosen habituation technique 32,33 and the use or not of the bone vibrator on the mastoid ${ }^{34}$, treatment is effective in about 70 to $90 \%$ of the cases ${ }^{20}$, and this percentage is not affected by patients' age ${ }^{35}$. Currently, those restrictions after repositioning measures were questioned, requiring studies that compared groups submitted to canalith repositioning maneuver (Epley) and liberatory maneuver (Semont) with and without instructions, but no differences were observed between the two studied groups 29,36-38. Such studies were conducted to minimize the discomfort caused by the restrictions imposed on patients after the conduction of the procedure.

\section{OBJECTIVE}

To assess the influence of posture guidance in early progression of patients with diagnosis of BPPV of posterior semicircular canal submitted to Epley maneuver.

\section{MATERIALSAND METHODS}

The present study was a randomized prospective study that comprised the period between January 2003 and June 2004. The protocol of investigations followed all ethical rules in place at Hospital das Clínicas, FMUSP.

The sample comprised 50 patients diagnosed as having posterior semicircular canal BPPV.

Inclusion criteria:

- Positive Dix-Hallpike test;

- Agreed to participate in the study.

Exclusion criteria:

- Presence of neck restrictions that prevented conduction of Epley Maneuver; 
- Use of antivertigo drugs.

Dix-Hallpike test was considered positive in case of triggering of dizziness and/ or presence of horizontal-rotation nystagmus, clockwise to left canal and anti-clockwise to the right canal, in Rose's position with hyperextension and lateral neck rotation. Subjects that agreed to participate in the study were submitted to both consecutive canalith repositioning maneuvers at the same time, as proposed by Epley*.

After repositioning, patients were randomized to two groups:

Control group, who was not instructed.

Studied group, who received post-maneuver instructions: sleep with high-positioned head using two pillows; not to perform sudden head movement, especially looking to the sides, up or down; not to sleep over the affected ear. The study flow chart can be seen in Figure 1.

Patients were reassessed $72+/-24$ hours after and divided into two groups: asymptomatic and symptomatic. The criteria for improvement were exclusion of main complaint (asymptomatic) and absence of dizziness and/or nystagmus in Dix-Hallpike test. We considered symptomatic the patients that reported partial improvement or absence of improvement after the maneuver and presented positive test result, even if in smaller amounts.

\section{Statistical Assessment}

The variables in the study were gender, age, and presence of residual symptoms associated with positive result of Dix-Hallpike test. We used Chi-square test to assess the collected results. The level of significance was 0.05 , as advocated for biological trials.

\section{RESULTS}

We analyzed 50 patients, 16 male and 34 female. Mean age of the studied population was $60.94+/-15.30$ years. As to laterality of affected canals, we found 29 cases of left posterior canals, and 21 right posterior canals.

The results obtained after the maneuvers of repositioning in relation to symptoms, gender and age of patients may be observed in Tables 1, 2 and 3 .

The difference of results between the group that was instructed and the group without instruction was not statistically significant $\left(\chi^{2}=0.97\right)$.

The observed evolution when comparing male and female genders did not present statistically significant difference $\left(\chi^{2}=0.80\right)$.

When assessing post-maneuver progression considering the different age ranges, we did not find statistically significant difference with the adopted value of $p=0.05\left(\chi^{2}=2.49\right)$.

\section{DISCUSSION}

According to our results, 37 (70\%) of the 50 patients became asymptomatic after Epley maneuver when assessed within $72 \pm 24$ hours after conduction of the procedure. Our data are in accordance with the literature, whose references point tow ards success rate of the maneuver in about $60 \%$ to $100 \%$ of the cases as an effective treatment approach of BPPV $21,28,39,40$

Table 1. Final results obtained in post-maneuver assessment in both studied groups.

\begin{tabular}{lccc}
\hline & asymptomatic & symptomatic & Total \\
\hline with instructions & 18 & 5 & 23 \\
without instructions & 17 & 10 & 27 \\
\hline Total & 35 & 15 & 50 \\
\hline
\end{tabular}

Table 2. Final results obtained in post-maneuver assessment classified by gender.

\begin{tabular}{lccc}
\hline & asymptomatic & symptomatic & total \\
\hline Female & 25 & 9 & 34 \\
Male & 9 & 7 & 16 \\
\hline Total & 34 & 16 & 50 \\
\hline
\end{tabular}

Table 3. Final results obtained in post-maneuver assessment classified by age.

\begin{tabular}{lccc}
\hline & asymptomatic & symptomatic & total \\
\hline Up to 40 years & 1 & 2 & 3 \\
40-60 years & 13 & 3 & 16 \\
60-70 years & 12 & 4 & 16 \\
$>$ de 70 years & 11 & 4 & 15 \\
\hline Total & 46 & 13 & 50 \\
\hline
\end{tabular}

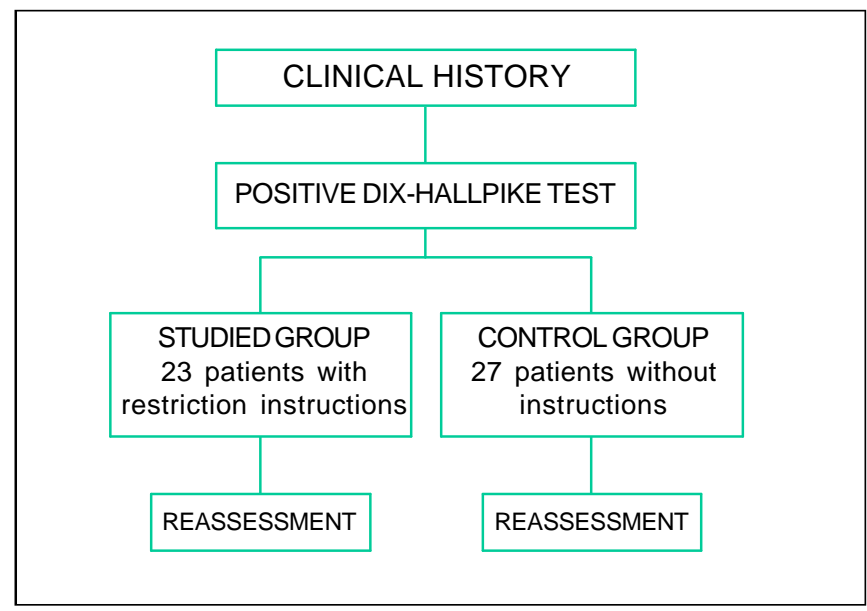

Figure 1. Sequential flow chart of the research method used. 
As to gender distribution, we observed predominance of female subjects (68\%), which is also in accordance with literature reports 2,42 . We should bear in mind, however, that even though BPPV prevalence studies report female predominance, when we consider younger age ranges, in which the main etiology is head trauma, the correlation between genders has no difference ${ }^{4}$. Despite clear female predominance, when considering clinical progression to treatment response, there were no statistically significant differences between genders.

The mean age of the studied population was 60.94 years and $31(62 \%)$ of the patients in the sample were aged over 60 years, as previous reports on prevalence and incidence of BPPV have demonstrated ${ }^{2,3}$. In the elderly, the diagnosis of BPPV is more frequent owing to associated co-morbidities ${ }^{8}$. In this age range, the disease normally has higher morbidity when associated with falls, which represents added risk to health and increased risk of mortality ${ }^{40,41}$. It is interesting to notice that even though the elderly are more exposed to the disease, we can observe that efficacy of repositioning maneuver is the same as the one observed in other age ranges, in accordance with previous reports ${ }^{35}$.

An interesting fact in this study was that only $33 \%$ of the younger patients, up to the age of 40 years, responded well to the procedure, differently from other subjects in the sample that reached improvement rate over $75 \%$. This isolated piece of data, even though not statistically significant, may be associated with etiology of the disease or still to the small sample in this age range, which comprised only three subjects. All these subjects presented history of head trauma that had triggered BPPV.

Even considering the possibility of self-resolution when treated with canalith repositioning maneuver, BPPV progresses better in the first month after the procedure, a fact that benefits patients and minimizes the duration of symptomatology $1,18,25,28,40,43$. However, the performance of the maneuver does not show substantial benefits in the long-term follow-up, between 3 and 6 months, nor in relation to the possibility of recurrence, which seems to be more related with etiology of vestibular affections that are associated with BPPV than to the symptomatic treatment adopted $18,44,45$. It seems clear that canalith repositioning is the recommended treatment in cases of BPPV, but the impact of instructions on posture restriction after the maneuver is still a controversial issue ${ }^{44}$. Upon describing his maneuver, Epley ${ }^{21}$ recommended, in addition to the use of bone vibrator, some posture restrictions and head movements after repositioning procedure. Among the care recommended, he suggested sleeping in a seated position or with $45^{\circ}$ elevation of the head for 48 hours after the maneuvers. Other authors ${ }^{27,28}$, who were stricter, recommended elevated head for 7 days after the maneuver, period in which sudden head movements and those that triggered dizziness would be avoided; not to sleep over the affected ear, and not to look up or down ${ }^{29}$. There were still others that instructed patients to wear a neck collar to prevent head movements $24,30,31$, a procedure not followed in our service owing to previous studies that suggested that neck collar and bone vibrator did not interfere in the outcomes of treatment ${ }^{5,44}$.

All propositions, even though based on anatomicalphysiological principles, make BPPV treatment a very disturbing approach to patients, who should take positions that they are not normally used to having, causing sensible affection to their quality of life. We should also consider that after the period of restrictions, patients may manifest great anxiety in view of the possibility of normally moving the head or sleeping over the affected the side to prevent sympto matology from restarting ${ }^{38}$. These facts potentially affect the elderly, which is known to be more fragile than younger people ${ }^{8}$ and present subsequent muscle pain when assuming any posture modification forced by the physician. We should bear in mind that the elderly population is significantly more affected by BPPV.

To get to know about the validity of post-maneuver instructions in relieving patients submitted to canalith repositioning, we randomized two groups and submitted them to posture restrictions recommended in the literature and did not give any instructions to the other group; we did not observe differences in the early clinical evolution of patients. The results are in accordance with those reported by other authors $29,36,38$ who did not detected better clinical evolution in patients submitted to different postures.

Concluding, treatment of BPPV with canalith repositioning maneuver is a simple option with satisfactory outcomes, regardless of posture restrictions traditionally recommended. The real etiology of BPPV is still questionable, but it seems clear that the initial proposition that repositioned particles would tend to get back to the posterior semicircular canal as a response to the position of the head is debatable. Only time and conduction of studies on the topic will clarify these facts. To present, it seems to be clear that there is no reason to submit our patients to these very uncomfortable recommendations.

\section{CONCLUSON}

O ur study suggested that Epley maneuver is an option for effective and safe treatment in $70 \%$ of the cases of BPPV approaching the posterior semicircular canal and posture restriction s post-maneuver studied in the present paper do not interfere in early progression of patients concerning symptomatology.

\section{REFERENCES}

1. Hilton $M$, Pinder $D$. The Epley maneuver for benign paroxysmal positional vertigo-a systematic review. Clin Otolaryngol 2002; 27: 440-5.

2. Mizukoshi K, Watanabe $\mathrm{Y}$, Shojaku $\mathrm{H}$ et al. Epidemiological study on benign paroxysmal positional vertigo. Acta Otolaryngol (Stockh) 1988: Suplem 447; 67-72. 
3. Froehling DA, Silverstein MD, Mohr DN et al. Benign positional vertigo: incidence and prognosis in a population-based study in OImsted County, Minnesota. Mayo Clin Proc 1991; 66: 596-601.

4. Katsarkas A. Benign Paroxysmal Positional Vertigo (BPPV): idiopathic versus post-traumatic. Acta Otolaryngol 1999; 119 (7): 745-9.

5. Parnes LS, Agrawal SK, Atlas J. Diagnosis and Management of benign paroxysmal positional vertigo. CMAJ 2003 Sept 30; 169 (7): 681-93.

6. Baloh RW, Honrubia V, Jacobson K. Benign positional vertigo: clinical and oculographic features in 240 cases. Neurology 1987; 37: 371-8.

7. Uneri A, Turkdogan D. Evaluation of vestibular functions in children with vertigo attacks. Arch Dis Child 2003 Jun; 88(6): 510-1.

8. Simoceli L, Bittar RSM, Bottino MA, Bento RF. Perfil do Idoso portador de desequilíbrio corporal: Resultados preliminares. Revista Brasileira de Otorrinolaringologia 2003; 69 (6): 772-7.

9. Kalberg M, Hall K, Quickert N, Hinson J, Halmagi GM. What inner ear diseases cause benign paroxysmal positional vertigo? Acta Otolaryngol 2000; 120: 380-5.

10. Hughes CA, Proctor I. Benign Paroxysmal positional vertigo. Laryngoscope 1997; 107: 607-13.

11. Gross EM, Ress BD, Virre ES, Nelson JR, Harris JP. Intractable benign paroxysmal positional vertigo in patients with Ménière's disease. Laryngoscope 2000; 110: 655-9.

12. Ishiyama A, Jacobson KM, Baloh RW. Migraine and benign positional vertigo. Ann Otol Rhinol Laryngol 2000; 109: 377-80.

13. Lempert $T$, Leopold $M$, von Brevern $M$, Neuhauser $H$. Migraine and benign positional vertigo. Ann Otol Rhinol Laryngol 2000; 109: 1176.

14. Atacan E, Sennaroglu L, Gene A, Kaya S. Benign paroxysmal positional vertigo after stapedectomy. Laryngoscope 2001; 111: 1257-9.

15. Collison PJ, Kolberg A. Canalith repositioning procedure for relief of post-stapedectomy benign paroxysmal positional vertigo. SDJ Med 1998; 51(3): 85-7.

16. Schuknecht HF. Positional vertigo: clinical and experimental observations. Trans Am Acad Ophthalmol Otolaryngol, 1962; 66: 319-332.

17. Hall SF, Ruby RRF, McClure JA. The mechanics of benign paroxysmal vertigo. J. Otolaryngol 1979; 8(2): 151-8.

18. Asawavichianginda $S$, Isipradit $P$, Snidvongs $K$, Supiyaphun $P$. Canalith repositioning for benign paroxysmal positional vertigo: a randomized, controlled trial. Ear Nose Throat J 2000; 79: 732-4.

19. Fujino A, Tokumasu $K$, Y osio $S$ et al. Vestibular training for benign paroxysmal positional vertigo: its efficacy in comparison with antivertigo drugs. Arch Otolaryngol Head Neck Surg 1994; 120: 497-504.

20. Kwanchanok $Y$, Srirompotong S, Srirompotong S. A randomized trial of the canalith repositioning procedure. Laryngoscope 2003; 113: 828-32.

21. Epley JM. The canalith repositioning procedure for treatment of benign paroxysmal positional vertigo. Otolaryngol Head Neck Surg 1992; 107: 399-404.

22. Semont A, Freyss G, Vitte E. Curing the BPPV with a liberatory maneuver. Adv Otorhinolaryngol 1988; 42: 290-3.

23. Norre ME, Forrez G, Backers A. Benign paroxysmal positional vertigo: clinical observations by vestibular habituation training and by posturography. J Laryngol Otol 1987; 101: 443-7.

24. Herdman SJ, Tusa RJ, Zee DS, et al. Single treatment approaches to benign paroxysmal positional vertigo. Arch Otolaryngol Head Neck Surg 1993; 119 (4): 450-4.
25. Steenerson RL, Cronin GW. Comparison of the canalith repositioning procedure and vestibular habituation training in forty patients with benign paroxysmal positional vertigo. Otolaryngol Head Neck Surg 1996; 114: 61-4.

26. Gacek RR. Singular neurectomy update II: review of 102 cases. Laryngoscope 1991; 101: 855-62.

27. Parnes LS, McClure JA. Posterior semicircular canal occlusion for intractable benign paroxysmal positional vertigo. ANN Otol Rhinol Laryngol 1990; 99: 330-4.

28. Lynn S, Pool A, Rose $D$, et al. Randomized trial of canalith repositioning procedure. Otolaryngol Head Neck Surg 1995; 113: 712-20.

29. Nuti D, Nati C, Passali D. Treatment of benign paroxysmal positional vertigo: no need for postmaneuver restrictions. Otolaryngol Head Neck Surg 2000; 122: 440-4.

30. Brandt T, Steddin S, Daroff RB. Therapy for benign paroxysmal positioning vertigo, revisited. Neurology 1994; 44: 796-800.

31. Li JC. Mastoid oscillation: a critical factor for success in the canalith repositioning procedure. Otolaryngol Head Neck Surg 1995; 112: 6705.

32. Soto VA, Bartual MJ, Santos, et al. Benign Paroxysmal Vertigo: a comparative prospective study of the efficacy of Brandt and Daroff exercises, Semont and Epley maneuver. Rev Laryngol Oto Rhinol 2001; 122: 179-83.

33. Bronstein AM. Benign Paroxysmal Positional Vertigo: some recent advances. Curr Opin Neurol 2003: 16: 1-3.

34. Hain TC, Helminski JO, Reis IL, Uddin MK. Vibration does not improve results of the canalith repositioning procedure. Arch Otolaryngol Head Neck Surg 2000; 126: 617-22.

35. Wolf M, Hertanu T, Novikov I, Kronenberg J. Epley's maneuver for benign paroxysmal positional vertigo a prospective study. Clin Otolaryngol 1999; 24: 43-6.

36. Massoud EA, Ireland DJ. Post-treatment instructions in the nonsurgical management of benign paroxysmal positional vertigo. J Otolaryngol 1996; 25: 121-5.

37. Marciano $\mathrm{E}$, Marcelli $\mathrm{V}$. Postural restrictions in labyrintholithiasis. Eur Arch Otorhinolaryngol 2002; 259: 262-5.

38. Cohen HS, Kimball KT. Treatment on Epley Maneuver for benign paroxysmal positional vertigo. Am J Otolaryngol 2004; 25(1): 33-7.

39. Blakley BW. A randomized controlled assessment of the canalith repositioning maneuver. Otolaryngol Head Neck Surg 1994; 110: 391-6.

40. Angeli SI, Hawley R, Gomez O. Systematic approach to benign paroxysmal vertigo in the elderly. Otolaryngol Head Neck Surg 2003; 128: 719-26.

41. Oghalai JS, Manolidis S, Barth JL, et al. Unrecognized benign paroxysmal positional vertigo in elderly patients. Otolaryngol Head Neck Surg, 2000; 122: 630-4.

42. Bourgeois PM, Dehaene I. Benign paroxysmal positional vertigo(BPPV). Clinical features in 34 cases and review of literature. Acta Neurol Belg 1988; 88: 65-74.

43. Macias JD, Ellensohn A, Massingale S, Gerkin R. Vibration With the Canalith Repositioning Maneuver: A Prospective Randomized Study to Determine Efficacy. Laryngoscope 2004; 114: 1011-4.

44. Woodworth BA, Gillespie MB, Lambert PR. The Canalith Repositioning Procedure for Benign Positional Vertigo: A MetaAnalysis. Laryngoscope 2004; 114: 1143-6.

45. Motamed M, Osinubi O, Cook JÁ. Effect of Mastoid Oscillation on the outcome of the Canalith Repositioning Procedure. Laryngoscope 2004; 114: 1296-8. 